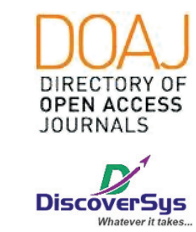

Published by DiscoverSys

\title{
Perubahan tekanan intraokuler pasca ekstraksi lensa pada pasien glaukoma sekunder akibat katarak senilis di Rumah Sakit Umum Pusat Sanglah Denpasar
}

\author{
Matthew Sebastian, ${ }^{*}{ }^{*}$ Made Agus Kusumadjaja, ${ }^{2}$ I Wayan Eka Sutyawan ${ }^{2}$
}

\section{ABSTRACT}

Background: Lens extraction in patients with glaucoma secondary to cataracts is regarded as the gold standard for treatment. In addition to increasing one's visual acuity after extraction of a cloudy lens, lens extraction may also reduce the patient's intraocular pressure, hence reducing the risk of long term vision loss and retinal damage.

Aims: This study aims to establish the link between different types of lens extraction procedures and intraocular pressure change, as well as establishing the link between hypertension and diabetes mellitus and the degree of intraocular pressure change.

Methods: This study is a retrospective cohort study involving 19 subjects with ongoing or a history of secondary glaucoma due to cataract. Research subjects are grouped based on the type of cataract extraction which they underwent and based on hypertension status and diabetes mellitus status. Acquired data is then analyzed descriptively and analytically.

Results: The average reduction of intraocular pressure in this study is $10.302 \mathrm{mmHg}$. Patients with hypertension had a statistically significant decrease in intraocular pressure change compared to patients without hypertension. The link between intraocular pressure change and diabetes mellitus remains to be inconclusive from this study.

Conclusion: Lens extraction lowers intraocular pressure in secondary glaucoma due to cataract patients. The type of lens extraction underwent by the patients affects the magnitude of intraocular pressure change. Patients with a history of hypertension has a significantly lower intraocular pressure change compared to those without history of hypertension.

Keywords: Glaucoma, cataract, lens extraction, phacoemulsification, hypertension, diabetes mellitus

Cite This Article: Sebastian, M., Kusumadjaja, M.A., Sutyawan, I.W.E. 2020. Perubahan tekanan intraokuler pasca ekstraksi lensa pada pasien glaukoma sekunder akibat katarak senilis di Rumah Sakit Umum Pusat Sanglah Denpasar. Intisari Sains Medis 11(2): 745-749. D0I: 10.15562/ism. v11i2.682

\section{ABSTRAK}

Latar Belakang: Ekstraksi lensa yang keruh pada pasien dengan glaukoma sekunder akibat katarak merupakan baku emas bagi terapi pasien dengan glaukoma sekunder akibat katarak. Selain peningkatan ketajaman penglihatan seseorang setelah ekstraksi lensa yang sudah keruh, ekstraksi lensa juga dapat menurunkan tekanan intraokuler seseorang, sehingga dapat berperan juga dalam managemen glaukoma seseorang.

Tujuan: Penelitian ini bertujuan untuk meneliti hubungan antara prosedur ekstraksi lensa terhadap penurunan tekanan intraokuler, serta meneliti hubungan antara status hipertensi dan diabetes mellitus terhadap perubahan tekanan intraokuler.

Metode: Penelitian ini merupakan penelitian kohor retrospektif yang melibatkan 19 subyek dengan glaukoma sekunder akibat katarak. Subyek penelitian dikelompokkan berdasarkan prosedur ekstraksi lensa yang dilakukan dan status hipertensi dan diabetes mellitus. Pengolahan data univariate dilakukan secara deskriptif dan analitik.

Hasil: Rata-rata penurunan tekanan intraokuler pasca operasi dari seluruh populasi ialah $10,302 \mathrm{mmHg}$. Nampaknya pasien dengan riwayat hipertensi akan mengalami penurunan tekanan intraokuler lebih sedikit dibandingkan pasien tanpa riwayat hipertensi. Pengaruh riwayat diabetes mellitus kepada penurunan tekanan intraokuler masih inkonklusif.

Kesimpulan: Prosedur ekstraksi lensa dapat menurunkan tekanan intraokuler pasien. Jenis ekstraksi lensa yang dilakukan berpengaruh terhadap besar perubahan tekanan intraokuler pasca ekstraksi lensa. Pasien dengan riwayat hipertensi mengalami perubahan tekanan intraokuler yang lebih kecil dibanding pasien tanpa riwayat hipertensi. Pengaruh diabetes terhadap perubahan tekanan intraokuler pasca ekstraksi lensa membutuhkan penelitian lebih lanjut. dan Pendidikan Dokter, Fakultas Kedokteran, Universitas Udayana, Bali-Indonesia

matthewsebastian1998@gmail.com

Diterima: $31-12-2019$

Disetujui: 027-06-2020

Diterbitkan: 01-08-2020
Kata kunci: Glaukoma, Katarak, Ekstraksi Lensa, Fakoemulsifikasi, Hipertensi, Diabetes Mellitus

Cite Pasal Ini: Sebastian, M., Kusumadjaja, M.A., Sutyawan, I.W.E. 2020. Perubahan tekanan intraokuler pasca ekstraksi lensa pada pasien glaukoma sekunder akibat katarak senilis di Rumah Sakit Umum Pusat Sanglah Denpasar. Intisari Sains Medis 11(2): 745-749. D0I: 10.15562/ism. v11i2.682 


\section{PENDAHULUAN}

Katarak dan glaukoma merupakan beberapa penyakit penyebab kebutaan terbesar di seluruh dunia. Di Asia Tenggara dan Oceania sendiri, katarak merupakan penyebab tertinggi dari kebutaan. ${ }^{1,2}$ Prevalensi kebutaan akibat katarak mencakup sekitar $47,8 \%$ dari lebih dari 37 juta orang buta di seluruh dunia, yang dimana dari $47,8 \%$ tersebut, 27,1\% terjadi di Asia Tenggara. ${ }^{1}$ Prevalensi dari kedua penyakit tersebut meningkat seiring dengan pertambahan usia. Ditemukan juga bahwa prevalensi glaukoma sekunder akibat katarak memuncak pada pasien dengan kisaran usia 60-70 tahun, yang dimana glaukoma fakomorfik merupakan subtipe yang lebih sering dijumpai dibandingkan glaukoma fakolitik. ${ }^{3,4}$ Penanganan yang terlambat atau tidak baik pada pasien dengan glaukoma dapat mengakibatkan peningkatan risiko dari kebutaan permanen berhubung peningkatan tekanan intraokuler dari mata akan mengakibatkan penekanan pada retina, sehingga dapat mengakibatkan degenerasi papil saraf optik yang juga dapat diakibatkan iskemi arteri yang mensuplai retina. ${ }^{4}$ Penanganan lebih awal dari tekanan intraokuler sangat penting untuk meminimalisir kemungkinan terjadinya kehilangan lapang pandang pasien ataupun kebutaan permanen.

Sudah terdapat banyak penelitian yang dilakukan di berbagai belahan dunia yang menunjukkan bahwa terdapat pengaruh signifikan dari ekstraksi lensa terhadap perubahan tekanan intraokuler pasien yang menderita glaukoma sekunder akibat katarak.,3,5 Prosedur ekstraksi lensa dapat mengurangi tekanan intraokuler seseorang pada pasien dengan glaukoma. ${ }^{5}$ Ditemukan bahwa tekanan intraokuler pasien-pasien ini menurun dari $23,2 \mathrm{mmHg}$ pre operasi hingga $19,8 \mathrm{mmHg}$ pasca operasi, penurunan sekitar 3,4 $\mathrm{mmHg}$, yang dimana penurunan ini berbanding lurus dengan besar tekanan intraokuler pasca operasi. ${ }^{7}$ Penurunan tekanan intraokuler ini nampaknya juga dipengaruhi oleh jenis prosedur ekstraksi katarak yang dilakukan oleh pasien. Prosedur fakoemulsifikasi nampaknya memiliki pengaruh yang lebih besar terhadap penurunan tekanan intraokuler pasien, yang diasumsikan diakibatkan karena energi kinetik residu hasil dari gelombang dari prosedur fakoemulsifikasi ${ }^{89}$ Namun, secara umum masih diperlukan studi lebih lanjut dari pengaruh ekstraksi lensa terhadap perubahan tekanan intraokuler bola mata.

\section{METODE}

Penelitian ini mempergunakan rancangan penelitian deskriptif kohor retrospektif. Penelitian dilakukan di Instalasi Rekam Medik RSUP Sanglah pada rentang waktu Oktober 2019-Desember 2019. Penelitian ini telah mendapatkan izin dari Komisi
Etik Penelitian Fakultas Kedokteran Universitas Udayana/Rumah Sakit Umum Pusat Sanglah Denpasar dengan nomor Ethical Clearance 1965/ UN14.2.2.VII.14/LP/2019 tertanggal 27 Juni 2019. Pengambilan dan pengumpulan data sekunder diperoleh dari registrasi rekam medis bagian Mata RSUP Sanglah Denpasar tahun 2018 - 2019. Teknik sampling yang digunakan adalah total sampling. Setelah dilakukan sampling, maka akan dilanjutkan dengan pengukuran besar perubahan tekanan intraokuler pasien pada tiap follow-up. Jumlah follow-up ialah menggunakan setidaknya 3 kali data pencatatan TIO pasca operasi sesuai pencatatan yang tercantum dalam rekam medis pasien, kemudian data TIO yang digunakan adalah data rata-rata dari 3 kali pencatatan tersebut.

Data penelitian akan dianalisis secara deskriptif melalui pembentukan tabel frekuensi, uji normalitas, dan histogram yang akan memberikan distribusi data berdasarkan perubahan tekanan intraokuler mata pre dan pasca operasi, dan pensajian analisis data deskriptif dari tekanan intraokuler pre operasi dan pasca operasi serta dengan selisihnya melalui grafik dan tabel. Data selisih tekanan intraokuler akan kemudian diuji menggunakan uji paired sample t-test.

Analisis univariat dilakukan dengan tujuan menentukan hubungan antar perubahan tekanan intraokuler pasca ekstraksi lensa jika dibandingkan dengan jenis ekstraksi lensa ataupun penyakit komorbid lainnya seperti hipertensi dan diabetes mellitus. Analisis dilakukan secara deskriptif untuk menghitung 95\% CI dari masing-masing grup ekstraksi lensa, status hipertensi, dan status diabetes.

\section{HASIL DAN DISKUSI}

Dari 45 rekam medik yang ditemukan melalui metode tersebut, diperoleh 19 kasus yang memenuhi kriteria inklusi pada tahun 20182019 setelah menempuh proses skrining manual. Adapun rata-rata usia dari usia pada penelitian ini ialah 61,1 tahun, dengan median usia 64 tahun. Gambar 1 menunjukkan histogram yang mencerminkan sebaran perubahan tekanan intraokuler berdasarkan kurva normalitasnya. Data cenderung berdistribusi normal, walaupun terdapat beberapa data yang tergolong sebagai pencilan/outlier. Uji t-test berpasangan telah dilakukan untuk menentukan signifikansi data antara TIO pre operasi dan TIO pasca operasi. Ditemukan bahwa perubahan TIO pre operasi dan pasca operasi signifikan secara statistik $(\mathrm{P}<0.001)$.

Dari seluruh populasi sampel $(\mathrm{n}=19), 13$ kasus merupakan dari pria, dan 6 kasus dari wanita. 


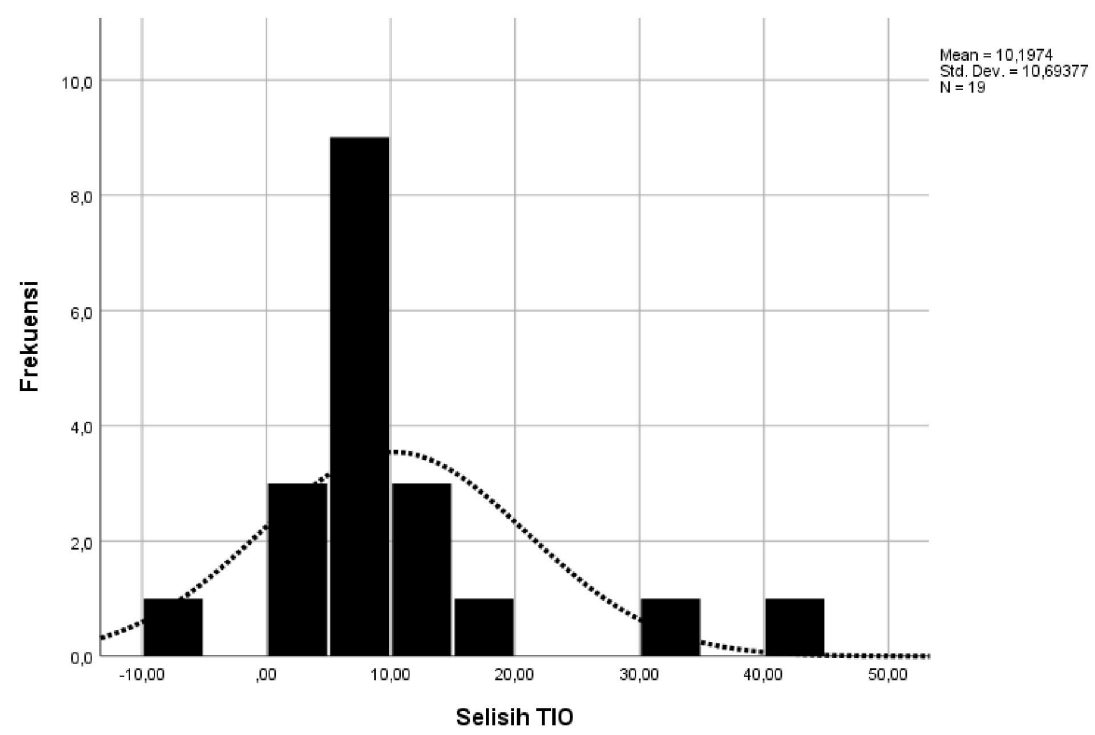

Gambar 1 Histogram dan garis normal dari selisih tekanan intraokuler pasien

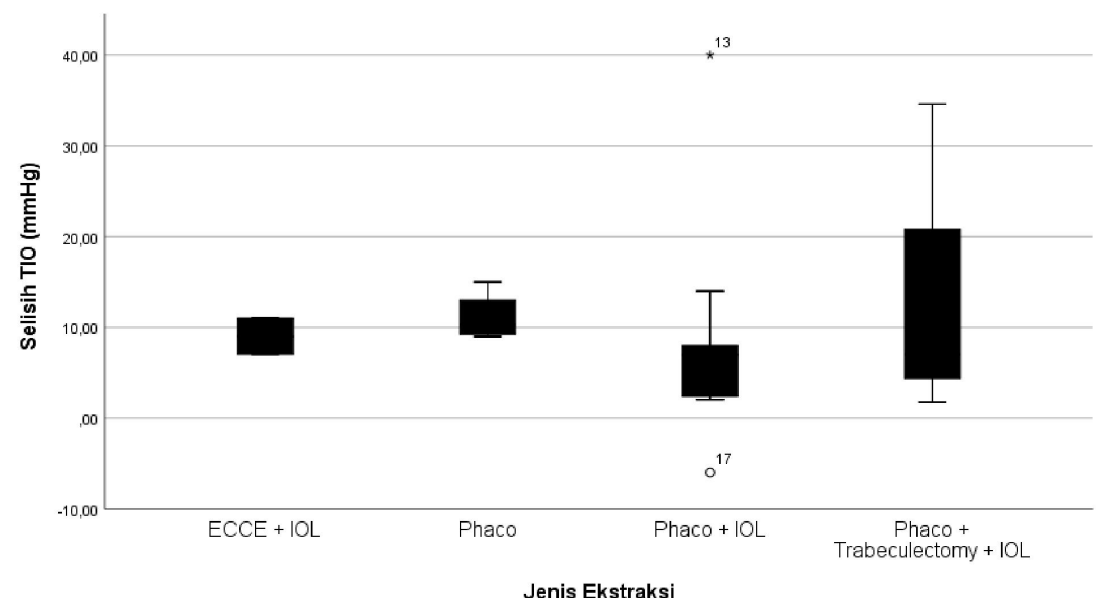

Gambar 2 Boxplot Selisih TIO Terhadap Jenis Ekstraksi Lensa. Ket: ECCE+ I: Extracapsular Cortical Cataract Extraction + Intraocular Lens Implantation, Phaco: Phacoemulsification, Phaco +: Phacoemulsification and Intraocular Lens Implantation, PTI: Phacoemulsification + Trabeculectomy + Intraocular Lens Implantation

\section{Tabel 1 Data Deskriptif Subjek Penelitian Berdasarkan Jenis} Prosedur Ekstraksi Lensa

\begin{tabular}{lcc}
\hline & Frekuensi & Persen \\
\hline ECCE+IOL & 2 & 10,5 \\
Fakoemulsifikasi & 4 & 21,1 \\
Fakoemulsifikasi + IOL & 10 & 52,6 \\
Fakoemulsifikasi + Trabekulektomi + IOL & 3 & 15,8 \\
Total & 19 & 100 \\
\hline
\end{tabular}

Ket: ECCE+IOL; Extracapsular Cataract Extraction + Intraocular Lens Implantation, Phaco: Phacoemulsification, Phaco + IOL; Phacoemulsification + Intraocular Lens Implantation, Phaco+Trabeculectomy+IOL; Phacoemulsification, Trabeculectomy and Intraocular Lens Implantation
Diperoleh 16 kasus katarak imatur dan 3 kasus katarak matur. Dari seluruh populasi sampel, 8 orang memiliki riwayat hipertensi, baik terkontrol ataupun masih aktif dan 3 memiliki riwayat diabetes mellitus. Dari 19 kasus tersebut, 2 orang menempuh prosedur ekstraksi lensa ECCE dan implantasi lensa buatan, 4 orang menempuh prosedur fakoemulsifikasi, 10 orang menempuh prosedur fakoemulsifikasi dan implantasi lensa buatan, dan 3 orang menempuh prosedur fakoemulsifikasi bersamaan dengan trabekulektomi dan implantasi lensa.

Tabel 2 menunjukkan data frekuensi dari pasien berdasarkan jenis ekstraksi lensa. Berdasarkan hasil t-test berpasangan yang dilakukan, ditemukan bahwa penurunan tekanan intraokuler pasca operasi dari seluruh jenis ekstraksi lensa signifikan secara statistik, dengan rata-rata penurunan $10,302 \mathrm{mmHg}(\mathrm{P}<0.001 ; 95 \% \mathrm{CI} 5,128-15,47)$.

Tabel 3 menjabarkan data analisis deskriptif dari selisih perubahan tekanan intraokuler berdasarkan jenis ekstraksi lensa yang ditempuh oleh pasien. Perubahan tekanan intraokuler berdasarkan jenis ekstraksi lensa disajikan dalam bentuk boxplot pada Gambar 2. Berdasarkan hasil analisis tersebut, dapat disimpulkan bahwa ketiga prosedur ekstraksi lensa, baik ECCE, fakoemulsifikasi, ataupun fakoemulsifikasi dengan trabekulektomi menunjukkan penurunan tekanan intraokuler yang berkisar dari 9-11 mmHg. Prosedur fakoemulsifikasi sendiri tanpa implantasi lensa intraokuler menunjukkan rata-rata penurunan tekanan intraokuler sebesar 11,1 mmHg (95\%CI 6,79-15,4). Walaupun demikian, perlu diingat bahwa sampel merupakan pasien yang sudah menempuh prosedur fakoemulsifikasi tanpa implantasi lensa intraokuler. Pada kelompok prosedur ECCE+I tidak signifikan secara statistik, namun hal tersebut dapat dijelaskan juga karena sampel yang cukup minim sehingga belum tentu ada nilai validasi eksternal.

Untuk prosedur ekstraksi lensa dengan metode fakoemulsifikasi, baik dengan atau tanpa implantasi lensa intraokuler memiliki hasil yang lebih signfikan secara statistik dalam penelitian ini. Pasien yang menempuh prosedur fakoemulsifikasi saja tanpa pemasangan lensa intraokuler memiliki rata-rata penurunan tekanan intraokuler sebesar $11,1 \mathrm{mmHg}(95 \% \mathrm{CI}=6,7-15,4)$, sedangkan pasien yang menempuh prosedur fakoemulsifikasi saja dengan pemasangan lensa intraokuler memiliki rata-rata penurunan tekanan intraokuler sebesar $8,79 \mathrm{mmHg}(95 \% \mathrm{CI}=0,11-17,4)$. Berdasarkan populasi sampel pada penelitian ini, pada kedua prosedur ini, penulis berhipotesis bahwa pemasangan lensa intraokuler dapat berpengaruh kepada perubahan tekanan intraokuler pasca ekstraksi lensa. 
Tabel 2 Data Deskriptif Tekanan Intraokuler Pasien

\begin{tabular}{lcccc}
\hline & Minimum & Maksimum & Mean & Standar Deviasi \\
\hline TIO Pre Operasi & 12,00 & 51,00 & 22,916 & 10,123 \\
TIO Pasca Operasi & 1,00 & 29,00 & 14,313 & 6,748 \\
Selisih TIO & $-8,00$ & 40,00 & 10,302 & 12,071 \\
\hline
\end{tabular}

Ket: SD; standar deviasi, TIO; tekanan intraokuler

Tabel 3 Analisis Deskriptif Selisih Tekanan Intraokuler PreEkstraksi dan Pasca-Ekstraksi Berdasarkan Jenis Prosedur Ekstraksi Lensa

\begin{tabular}{lccc}
\hline Jenis Prosedur & Mean & $\mathbf{9 5 \% C l}$ & $\begin{array}{c}\text { Standard } \\
\text { Error }\end{array}$ \\
\hline ECCE+IOL & 9,000 & $-16,412-34,412$ & 2,000 \\
Fakoemulsifikasi & 11,125 & $6,797-15,452$ & 1,359 \\
Fakoemulsifikasi + IOL & 8,790 & $0,110-17,470$ & 3,837 \\
Fakoemulsifikasi+Trabekulektomi+IOL & 14,450 & $-29,386-58,286$ & 10,188 \\
\hline
\end{tabular}

Ket: ECCE; Extracapsular Cataract Extraction, IOL; Intraocular Lens, CI; Confidence Interval

Tabel 4 Analisis Deskriptif Selisih TIO Berdasarkan Status Hipertensi

\begin{tabular}{lccc}
\hline Status Hipertensi & Mean & $\mathbf{9 5 \%} \mathbf{C l}$ & Standar Error \\
\hline Hipertensi & 6,906 & $4,084-9,728$ & 1,193 \\
Tidak Hipertensi & 12,590 & $3,505-21,676$ & 4,077 \\
\hline
\end{tabular}

Tabel 5 Analisis Deskriptif Selisih TIO Berdasarkan Status Diabetes

\begin{tabular}{lccc}
\hline Status Diabetes & Mean & $\mathbf{9 5 \% C l}$ & Standar Error \\
\hline Diabetes & 14,450 & $-29,386-58,286$ & 10,188 \\
Tidak Diabetes & 9,400 & $4,305-14,494$ & 2,390 \\
\hline
\end{tabular}

Pasien yang menempuh prosedur fakoemulsifikasi, trabekulektomi, dan pemasangan lensa intraokuler memiliki penurunan tekanan intraokuler yang cukup tinggi dibandingkan dengan ketiga prosedur lainnya. Hal ini dapat dijelaskan oleh karena kombinasi pengaruh modalitas fakoemulsifikasi terhadap tekanan intraokuler, dan peningkatan outflow dari aqueous humor menuju sklera dan bermuara ke konjungtiva, sehingga mampu menurunkan TIO secara efektif. ${ }^{10,11}$ Hal tersebut selanjutnya akan berdampak pada keterkaitan jalur visual yang dipersepsi oleh cortex cerebral. ${ }^{12}$

Tabel 4 dan 5 menjabarkan data deskriptif dari penurunan tekanan intraokuler pasca operasi pada pasien dengan hipertensi dan diabetes. Rata-rata dari penurunan tekanan intraokuler pada pasien dengan riwayat hipertensi adalah $6,9 \mathrm{mmHg}$ $(95 \% \mathrm{CI}=4,08-9,72)$. Penurunan ini lebih rendah jika dibandingkan dengan kelompok pasien tanpa status hipertensi, dengan rata-rata penurunan tekanan intraokuler sebesar 12,59 (95\%CI=3,5-21,6). Kedua data pasien baik pada kelompok hipertensi dan kelompok sehat signifikan secara statisik. Dapat disimpulkan bahwa pada populasi pasien yang memiliki riwayat hipertensi aktif ataupun terkontrol memiliki penurunan tekanan intraokuler yang lebih sedikit dibandingkan pasien tanpa riwayat hipertensi aktif ataupun terkontrol. Hal ini sepadan dengan penemuan sebelumnya yang menemukan korelasi antar peningkatan tekanan intraokuler dan hipertensi sistemik. ${ }^{13}$ Namun, sejauh ini belum ditemukan literatur yang menunjukkan hubungan langsung antara hipertensi dan penurunan tekanan intraokuler setelah ekstraksi lensa.

Tabel 5 menjabarkan analisis deksriptif selisih tekanan intraokuler berdasarkan status diabetes. Walaupun ada perbedaan antara rata-rata perubahan tekanan intraokuler antara populasi pasien dengan riwayat diabetes mellitus, namun data tersebut tidak signifikan secara statistik jika dilihat dari 95\%CI $(95 \% \mathrm{CI}=-29,3-58,2)$. Pada penelitian ini, hubungan antara diabetes mellitus dan penurunan tekanan intraokuler pasca ekstraksi lensa tidak signifikan secara statistik. Hal ini juga bisa diakibatkan oleh terbatasnya sampel pasien yang memiliki riwayat diabetes mellitus dalam penelitian ini, sehingga populasi pasien diabetes tidak bisa mewakili keadaan sebetulnya.

\section{KETERBATASAN PENELITIAN}

Penelitian ini memiliki beberapa keterbatasan. Pertama, populasi penelitian yang terjangkau dalam penelitian ini hanya data rekam medik RSUP Sanglah yang memiliki riwayat glaukoma sekunder akibat katarak dari satu tahun terakhir saja. Kedua, jumlah sampel yang relatif sedikit sehingga penulis menilai dibutuhkan penelitian lanjutan dalam skala yang lebih besar untuk memvalidasi penemuanpenemuan yang ditemukan dalam penelitian ini.

\section{KESIMPULAN}

Berdasarkan penelitian yang sudah dilakukan, dapat disimpulkan bahwa terdapat perubahan tekanan intraokuler yang signifikan pasca ekstraksi lensa. Keempat prosedur ekstraksi lensa yang diteliti pada penelitian ini menunjukkan besar perubahan tekanan intraokuler yang bervariasi. Pemasangan lensa intraokuler nampaknya berkaitan dengan perubahan tekanan intraokuler pasien pasca ekstraksi lensa, namun masih diperlukan kohor yang lebih besar untuk memvalidasi klaim tersebut. Adapun prosedur ekstraksi lensa yang menunjukkan penurunan yang paling besar ialah fakoemulsifikasi dengan trabekulektomi dan pemasangan lensa intraokuler, namun data tersebut masih kurang signifikan secara statistik dan 
membutuhkan kohor validasi yang lebih besar sampelnya. Pasien dengan riwayat hipertensi memiliki penurunan tekanan intraokuler yang lebih rendah dibandingkan pasien tanpa riwayat hipertensi. Pengaruh diabetes terhadap perubahan tekanan intraokuler pasca ekstraksi lensa membutuhkan penelitian lebih lanjut.

\section{DAFTAR PUSTAKA}

1. Chan EWE, Li X, Tham YC, Liao J, Wong TY, Aung T, et al. Glaucoma in Asia: Regional prevalence variations and future projections. British Journal of Ophthalmology. 2016; Vol. 100: 78-85. https://dx.doi.org/10.1136/ bjophthalmol-2014-306102

2. Keeffe JE, Casson RJ, Pesudovs K, Taylor HR, Cicinelli MV, Das A, et al. Prevalence and causes of vision loss in South-east Asia and Oceania in 2015: Magnitude, temporal trends and projections. $\mathrm{Br} J$ Ophthalmol. 2019;103(7):878-84. DOI: http://dx.doi.org/10.1136/ bjophthalmol-2018-312068

3. Peram V, Atti S, Paspula R, Arikeri K, Shiva S, Marrevula V. Clinical types, IOP Control and Visual Outcome in Lens Induced Glaucoma. J Evol Med Dent Sci. 2015;4(92):15798801. https://dx.doi.org/10.14260/jemds/2015/2284

4. Rao P. A Clinical Study on Visual Outcome \& Visual Prognostic Factors of Lens Induced Glaucoma. J Evol Med Dent Sci. 15 Mei 2015;4(40):6960-6. DOI: https://dx.doi. org/10.14260/jemds/2015/1011

5. Singh K, Cheema A, Kung J, Choi D. Cataract surgery in the glaucoma patient. Middle East Afr J Ophthalmol [Internet]. 2015 [dikutip 30 Desember 2019];22(1):10. Tersedia pada: https://dx.doi.org/10.4103/0974-9233.148343

6. Baek SU, Kwon S, Park IW, Suh W. Effect of phacoemulsification on intraocular pressure in healthy subjects and Glaucoma patients. J Korean Med Sci. 18 Februari 2019;34(6). http://dx.doi.org/10.3346/jkms.2019.34.e47
7. Mansberger SL, Gordon MO, Jampel H, Bhorade A, Brandt JD, Wilson B, et al. Reduction in intraocular pressure after cataract extraction: The ocular hypertension treatment study. Ophthalmology. 2012;119(9):1826-31. DOI: https://doi.org/10.1016/j.ophtha.2012.02.050

8. Melancia D, Abegão Pinto L, Marques-Neves C. Cataract Surgery and Intraocular Pressure. Ophthalmic Res [Internet]. 2015 [dikutip 30 Desember 2019];53(3):141-8. DOI: https://doi.org/10.1159/000377635

9. Lee RY, Chen RI, Kasuga T, Cui QN, Porco TC, Lin SC. The Effect of Cumulative Dissipated Energy on Changes in Intraocular Pressure after Uncomplicated Cataract Surgery by Phacoemulsification. In: Journal of Glaucoma. Lippincott Williams and Wilkins; 2016. hal. 565-70. DOI: https://dx.doi.org/10.1097/IJG.0000000000000311

10. Tseng VL, Coleman AL, Chang MY, Caprioli J. Aqueous shunts for glaucoma. Cochrane Database of Systematic Reviews. John Wiley and Sons Ltd; 2017. DOI: https://doi. org/10.1002/14651858.CD004918.pub3

11. Konstas AGP, Quaranta L, Bozkurt B, Katsanos A, GarciaFeijoo J, Rossetti L, et al. 24-h Efficacy of Glaucoma Treatment Options. Vol. 33, Advances in Therapy. Springer Healthcare; 2016. hal. 481-517. DOI: http://dx.doi. org/10.1007/s12325-016-0316-7

12. Wirata G, Karmaya INM, Muliarta IM. Long-term visual deprivation inhibit the visual lobe neocortex cytoarchitecture increment in 42 days male rats (Rattus norvegicus): a stereological study. Indonesian Journal of Biomedical Science. 2019;13(1): 48-52. DOI:10.15562/ijbs.v13i1.183

13. Leeman M, Kestelyn P. Glaucoma and Blood Pressure. Hypertens (Dallas, Tex 1979) [Internet]. 2019 [dikutip 30 Desember 2019];73(5):944-50. DOI: https://doi. org/10.1161/HYPERTENSIONAHA.118.11507

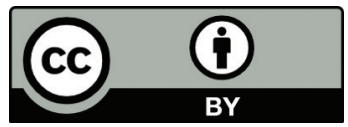

This work is licensed under a Creative Commons Attribution 